\title{
Association Between Obstructive Sleep Apnea and Stroke and Contributory Risk Factors
}

\author{
Ho Geol Woo ${ }^{1}$, Kwang Ik Yang ${ }^{2}$, Tae-Jin Song ${ }^{3}$ \\ ${ }^{1}$ Department of Neurology, Kyung Hee University College of Medicine, Seoul, \\ ${ }^{2}$ Sleep Disorders Center, Department of Neurology, Soonchunhyang University Cheonan Hospital, \\ Soonchunhyang University College of Medicine, Cheonan, \\ ${ }^{3}$ Department of Neurology, Ewha Womans University Seoul Hospital, Ewha Womans University College of Medicine, Seoul, Korea
}

\section{폐쇄수면무호흡과 뇌졸중 및 위험인자간의 연관성}

\author{
우호걸 ${ }^{1}$, 양광익 ${ }^{2}$, 송태진 ${ }^{3}$ \\ ${ }^{1}$ 경희대학교 의과대학 신경과학교실, ${ }^{2}$ 순천향대학교 의과대학 천안병원 신경과학교실, ${ }^{3}$ 이화여자대학교 의과대학 서울병원 신경과학교실
}

Received October 21, 2021

Revised November 18, 2021

Accepted November 29, 2021

Address for correspondence

Tae-Jin Song, MD, PhD

Department of Neurology,

Ewha Womans University

Seoul Hospital,

Ewha Womans University

College of Medicine,

260, Gonghang-daero,

Gangseo-gu,

Seoul 07804, Korea

Tel: +82-2-6986-2677

Fax: +82-2-6986-5958

E-mail: knstar@ewha.ac.kr

Kwang Ik Yang, MD, PhD

Sleep Disorders Center,

Department of Neurology,

Soonchunhyang University

Cheonan Hospital,

Soonchunhyang University

College of Medicine

31 Suncheonhyang 6-gil,

Dongnam-gu,

Cheonan 31151, Korea

Tel: +82-41-570-2290

Fax: $+82-41-592-3810$

E-mail: neurofan@schmc.ac.kr
Obstructive sleep apnea (OSA), a common comorbidity in patients with stroke, has shown increasing prevalence over the past few decades. OSA is an important risk factor for stroke in addition to other well-known contributors, including hypertension, hyperlipidemia, atrial fibrillation, and diabetes mellitus. Moreover, OSA is an independent predictor of neurological outcomes and mortality. The pathological mechanisms underlying the association between OSA and stroke include autonomic dysfunction, hypertension, cardiac arrhythmia, dyslipidemia, impaired glucose tolerance, hypoxia, and inflammation. Continuous positive airway pressure (CPAP) therapy has proven clinical utility in improvement of neurological symptoms in patients with stroke. Findings from a CPAP withdrawal model have shown increased sympathetic activity in OSA with a consequent significant elevation in blood pressure, relevant cerebral hypoxia, and disturbed cardiac repolarization. In this review, we present an overview of the literature that describes an association between OSA and stroke in addition to the vascular risk factors, including hypertension, hyperlipidemia, atrial fibrillation, and diabetes mellitus. This study highlights the importance of early and accurate diagnosis and management of OSA for stroke prevention and care and will benefit physicians in clinical practice.

J Sleep Med 2021;18(3):119-126

Keywords: Sleep; Sleep apnea, obstructive; Stroke.

\section{서 론}

폐쇄수면무호흡(obstructive sleep apnea, OSA)은 1836년

This is an Open Access article distributed under the terms of the Creative Commons Attribution Non-Commercial License (https://creativecommons.org/licenses/by-nc/4.0) which permits unrestricted non-commercial use, distribution, and reproduction in any medium, provided the original work is properly cited.
에 Charles Dickens의 소설에 처음으로 등장했다. ${ }^{1}$ 1965년 Gastaut 등 2 은 비만환자의 야간수면검사(nocturnal polygraphy)를 통해 수면무호흡(sleep apnea)을 확인하였다. 1972년 Rimini 국제회의에서 폐쇄수면무호흡증후군(obstructive sleep apnea syndrome, OSAS)의 개념이 처음으로 정립되었다.

폐쇄수면무호흡 환자에게 흔히 관찰되는 snoring은 상기 
도의 좁아진 부위를 공기가 통과하면서 생긴 기압 차 때문에 이완된 연구개와 구개수, 주위 구조물들이 진동하여 생기는 호흡 잡음으로, 수면중에 공기의 흐름을 유지하는 상기도를 조절하는 뇌-신경-근 기능이 저하되어 상기도의 저항 증가 로 발생된 호흡 또는 숨의 진동으로 인한 소리이다. 수면호흡 조절 중추가 뇌라는 점을 고려하면 '(수면)숨골이’라는 용어 가 이 소리의 발생기전을 정확히 반영하는 용어라 할 수 있 다. ${ }^{4}$ 그러므로 이 종설에서는 snoring을 숨골이로 표현하겠다.

폐쇄수면무호흡은 수면 중 상기도에 완전 또는 부분적 폐 쇄가 반복적으로 나타나 공기 흐름 제한, 산소포화도 감소, 잦은 각성을 유발하여 다양한 야간 또는 주간 증상이 생기는 흔한 수면관련호흡장애(sleep related breathing disorder)로 성인에서 2\%-4\%의 발병률을 보이고 나이가 들수록 증가하 며, 국내 역시 남자 $4.5 \%$, 여자 $3.2 \%$ 로 비슷한 유병률을 보인 다. 폐쇄수면무호흡은 수면다원검사를 통한 국제수면장애분 류(International Classification of Sleep Disorders-3) 진단 기 준에 의해 진단을 내린다. ${ }^{5}$ 수면다원검사에서 호흡장애지수 [respiratory disturbance index $=$ (무호흡 + 저호흡 + 호흡노력 각성)의 횟수/수면 시간가 5 이상이면서 이와 관련한 증상 이 있는 경우에 폐쇄수면무호흡으로 정의한다. 관련 증상에 는 주간졸림, 피로, 자고 나도 개운치 않은 불면증, 숨골이 및 수면무호흡 관찰이 포함되며, 이 중 하나만 있으면 진단할 수 있다. 또한, 환자에게 관련 증상이 없어도 호흡장애지수가 15 이상이면 폐쇄수면무호흡으로 정의한다. 폐쇄수면무호흡 의 정도는 수면다원검사를 통해 시간당 무호흡-저호흡지수 (apnea-hypopnea index, $\mathrm{AHI})$ 에 따라 정상 $(\mathrm{AHI}<5)$, 경도 $(5 \leq \mathrm{AHI}<15)$, 중등도 $(15 \leq \mathrm{AHI}<30)$, 중증 $(\mathrm{AHI} \geq 30)$ 으로 나뉘며, 호흡장애지수와 혼용하여 사용하기도 한다. 1981년 Sullivan 등 ${ }^{6}$ 이 처음으로 고안한 지속기도양압(continuous positive airway pressure)은 양압을 발생하는 기계로부터 압 력이 튜브 및 마스크를 통해 상기도로 전달됨으로써 상기도 가 막히는 것을 방지하는 방법으로서 대표적인 폐쇄수면무 호흡의 주요 치료법으로 발전하여 임상에서 널리 적용되고 있다.

20세기 후반부터 폐쇄수면무호흡과 숨골이는 고혈압, ${ }^{7}$ 부 정맥, ${ }^{8}$ 관상동맥질환과 심근경색, ${ }^{9}$ 뇌경색 ${ }^{10}$ 의 독립적인 위험 인자로 인식되기 시작하였다. 국내에서 시행된 연구에서도 폐쇄수면무호흡 고위험군에서 고혈압, 당뇨, 고지혈증이 의 미있게 동반되는 것이 입증되었다. ${ }^{11-13}$ 본 종설에서는 폐쇄수 면무호흡과 뇌졸중 및 뇌졸중 위험인자 사이의 연관성에 대 해 알아보고자 한다.

\section{본 론}

\section{폐쇄수면무호흡과 고혈압 및 야간혈압하강의 소실}

폐쇄수면무호흡은 고혈압 및 야간혈압하강의 소실(nondipping pattern of nocturnal blood pressure)과 밀접하게 연 관되어 있다. 고혈압 환자의 30\%-83\%에서 폐쇄수면무호흡 이 나타나며, ${ }^{14}$ 중등도-중증 폐쇄수면무호흡이 고혈압의 유 병률 및 발생률을 높인다고 알려져 있다. 또한, 중증 폐쇄수 면무호흡 환자는 그렇지 않은 환자와 비교하였을 때 저항성 고혈압을 가지는 비율이 4배 높다. ${ }^{15}$ 폐쇄수면무호흡과 혈압 사이에는 소위 용량-반응 관계(dose-response relationship) 가 있는데, 즉 폐쇄수면무호흡의 중증도가 높을수록 혈압이 상승한다. ${ }^{16}$ 또한, 폐쇄수면무호흡과 야간혈압하강의 소실 사 이에도 용량-반응 관계가 있다. ${ }^{17}$

이런 관계를 설명하는 기전으로 폐쇄수면무호흡이 수면 중 저산소혈증 및 잦은 각성을 일으켜 교감신경의 활동을 증가 시키고 자율신경기능부전을 초래하며, 그로 인해 야간혈압 하강(dipping pattern of nocturnal blood pressure)이 나타나 지 않게 되고, ${ }^{18}$ 이렇게 증가된 교감신경의 활동과 야간혈압 하강의 소실이 고혈압을 초래한다는 가설이 제시되고 있다.

이런 폐쇄수면무호흡을 치료하였을 때, 즉 폐쇄수면무호 흡 환자에게 지속기도양압 치료를 적절히 시행하였을 때, 야 간혈압하강이 나타나며 고혈압 발생의 위험성은 낮아진다. ${ }^{19}$ 폐쇄수면무호흡과 저항성 고혈압을 동시에 가지는 환자를 대상으로 한 이전 연구에서는 12 주 동안의 지속기도양압 치 료가 24시간 평균 혈압 및 24시간 이완기 혈압, 야간혈압하 강에 효과적이라고 보고했다. ${ }^{20}$

\section{폐쇄수면무호흡과 당뇨병, 인슐린 저항성, 혈당조절}

폐쇄수면무호흡은 비록 당뇨병 위험인자 중 하나인 비만과 관련이 있다는 이슈가 있기는 하지만 독립적으로도 당뇨병 과 밀접하게 연관되어 있다. 이런 연관성을 설명하는 기전으 로, 폐쇄수면무호흡이 인슐린 저항성의 증가, 포도당 불내성, 카테콜아민 분비 증가, 코티솔 분비 증가를 초래하여 혈당을 증가시키고 당뇨병을 촉발시킨다고 알려져 있으며, 비만의 동반 여부를 고려한 후에도 독립적으로 인슐린 저항성의 증 가를 일으킨다고 알려져 있다. ${ }^{21}$ 폐쇄수면무호흡은 비만을 동 반한 당뇨병 환자의 $86 \%$ 에서 관찰되며, 폐쇄수면무호흡의 중증도를 반영하는 무호흡-저호흡지수가 1 증가할 때 인슐린 저항성을 반영하는 공복 혈중 인슐린과 homeostatic model assessment-insulin resistance가 $0.5 \%$ 증가한다고 한다. 22,23

폐쇄수면무호흡이 있는 당뇨병 환자는 6개월간 지속기도 양압 치료를 적절하게 받았을 때 그렇지 않은 환자와 비교하 
여 유의하게 당화혈색소가 감소하였다(-0.4\%; $95 \%$ confidence interval, $-0.7 \%$ to $-0.04 \%) .{ }^{24}$ 지속기도양압 치료의 경 우 환자가 잘 적응하지 못하여 치료에 실패하는 경우들이 종 종 있다. 지속기도양압 치료가 잘 적용될 수 있도록 관리하는 것은 중요하다. 실제로, 당뇨환자에게 적절하게 지속기도양 압 치료를 시행했을 경우 혈당조절이 양호하였으며 인슐린 저항성도 개선되었다. ${ }^{25}$ 그러나 이러한 현상이 비만과 함께 조절되었을 수도 있기 때문에, 지속기도양압 치료와 혈당조 절, 당뇨병에 대해서는 좀더 연구가 필요하다.

\section{폐쇄수면무호흡과 심방세동}

심방세동은 뇌졸중의 중요한 위험 인자이며 특히 심방세동 으로 인한 뇌졸중은 예후가 나쁘고 사망가능성도 높기 때문 에, 심방세동을 예방하고 적절하게 치료하는 것은 뇌졸중 발 생을 예방하고 재발을 방지하기 위해 무엇보다 중요하다. 이 런 심방세동은 폐쇄수면무호흡과 밀접하게 연관되어 있다.

최근 발표된 유럽심장학회의 진료지침에서 폐쇄수면무호 흡이 있는 환자는 심방세동이 있는지 확인이 필요하다고 새 롭게 강조되었다. ${ }^{26}$ 일반인구집단을 대상으로 한 Sleep Heart Health Study는 폐쇄수면무호흡이 있는 사람이 폐쇄수면무 호흡이 없는 사람에 비하여 약 5 배가량 심방세동의 유병률이 높았다고 밝혔다(5\% vs. $1 \%){ }^{27}$ 또한 폐쇄수면무호흡은 증상 성 심방세동과 연관성이 있다. 증상성 심방세동의 약 $40 \%$ 는 자정부터 오전 8:00시 사이, 즉 수면무호흡이 발생할 가능성 이 높은 시간대에 나타나며, ${ }^{28}$ 폐쇄수면무호흡의 정도가 심할 수록 심방세동이 발생할 위험성도 높아진다..$^{29}$ 이러한 폐쇄수 면무호흡과 심방세동의 밀접한 연관성은 환자를 대상으로 한 연구에서도 동일하게 제시된 바 있다. 관상동맥혈관수술 을 받은 환자를 대상으로 한 이전 연구에서 폐쇄수면무호흡 의 중증도를 반영하는 무호흡-저호흡지수가 높을수록 향후 심방세동의 발생 위험성이 높았다. ${ }^{30}$

폐쇄수면무호흡은 다양한 기전으로 심방세동을 일으킨다 고 알려져 있다. 폐쇄수면무호흡으로 무호흡이 발생하게 되 면 흥곽 내의 음압이 증가하게 된다. 흥곽 내에 음압이 증가 하게 되면 심장박동에 작용하는 미주신경의 조절기능에 이 상을 초래하여 심방세동을 비롯한 부정맥의 발생가능성이 높아지게 된다. ${ }^{31}$ 또한 폐쇄수면무호흡은 심방세동 발생에 중 요 부위인 심방의 부착부위(anchoring regions of atria)의 섬 유화(fibrosis)와 stretch-sensitive ion channels를 활성화 시켜 심방세동을 비롯한 부정맥의 발생 위험성을 증가시킨다. ${ }^{32,33}$

지속기도양압 치료가 심방세동에 미치는 효과와 관련된 연구들도 있다. 폐쇄수면무호흡을 동반한 심방세동환자에서 $\mathrm{DC}$ 심장율동전환(cardioversion)을 시행 후 1년간 추적관찰
하였을 때, 적절하게 지속기도양압 치료를 지속해서 받은 환 자는 지속기도양압 치료를 받지 않았거나 부적절하게 받은 환자에 비해 절반 가까이 심방세동 재발 가능성이 낮았다. ${ }^{34}$ 또한, 폐쇄수면무호흡을 동반한 심방세동환자에서 부정맥 차단술(ablation)을 시행 후 지속기도양압 치료가 적절하게 시행되지 않은 환자는 적절하게 지속기도양압 치료를 받은 환자보다 시술 후 심방세동 재발의 가능성이 더 높음을 확인 하였다. ${ }^{35}$ 따라서, 뇌졸중의 중요 위험인자인 심방세동을 적 절하게 조절하고 치료하기 위해서는 폐쇄수면무호흡의 동반 여부를 확인하고, 폐쇄수면무호흡이 확인된 경우 적절한 치 료를 시행하는 것이 중요하다.

\section{폐쇄수면무호흡과 뇌졸중}

폐쇄수면무호흡은 앞서 언급한 고혈압, 당뇨병, 심방세동 같은 대표적인 혈관질환의 위험인자들에 영향을 미쳐 뇌졸 중의 위험을 간접적으로 증가시키기도 하지만, 폐쇄수면무 호흡 자체가 뇌졸중의 독립적인 위험인자이기도 하다. 미국 뇌졸중학회에서 발간한 뇌졸중 예방을 위한 진료지침에서 는 뇌졸중 환자에서 폐쇄수면무호흡의 빈도가 높고, 폐쇄수 면무호흡 치료시 뇌졸중의 예후를 호전시키므로 뇌졸중 환 자에서 폐쇄수면무호흡이 있는지 확인해야 한다고 하였다 (Class IIB, Level of Evidence B). ${ }^{36}$

Yaggi 등 ${ }^{37}$ 이 발표한 기념비적인 연구에서 무호흡-저호흡 지수가 35 이상인 폐쇄수면무호흡 환자는 무호흡-저호흡지 수가 35 미만인 환자들과 비교하였을 때 뇌졸중의 발생 위 험성 및 사망가능성이 두배 이상 높음을 확인하였다. 또한 무 호흡-저호흡지수의 증가는 대표적인 혈관질환의 위험인자 들을 모두 고려하더라도 독립적으로 뇌졸중 발생과 연관되어 있었다. ${ }^{38}$ 일반 인구집단을 대상으로 한 Sleep Heart Health Study에서는 무호흡-저호흡지수가 높은 남자(AHI>19)의 경우, 그렇지 않은 남자와 비교하였을 때 뇌졸중 발생 위험성 이 2.9배 높았다. 또한, 경도-중등도의 폐쇄수면무호흡(AHI, 5-25)을 가지는 사람에서 무호흡-저호흡지수가 1 증가시 뇌 졸중 발생 위험성이 $6 \%$ 증가하였다. 여자의 경우에는 무호 흡-저호흡지수가 25 를 초과하였을 때 뇌졸중의 위험성이 유 의하게 증가하였다. 폐쇄수면무호흡과 뇌졸중의 연관성에 대한 연구들의 결과는 Table 1 에 기술하였다. ${ }^{39-41}$

또한, 폐쇄수면무호흡은 뇌졸중의 간접지표와도 밀접하게 연관되어 있다. 중등도-중증 폐쇄수면무호흡은 백질변성, 열 공성 뇌경색, 미세출혈을 포함한 소혈관질환과 연관되어 있 으며, ${ }^{42-44}$ 경동맥 및 뇌내동맥의 동맥경화와 연관이 있다. ${ }^{45,46}$ 최근 연구에서, 급성 허혈성뇌졸중 환자에서 증상성 뇌내동맥 의 석회화는 폐쇄수면무호흡의 고위험군과 연관이 있었다. ${ }^{47}$ 
Table 1. Studies of OSA at risk for stroke

\begin{tabular}{|c|c|c|c|c|c|}
\hline Study & Design & Number & Group & Primary outcome* & Risk factor adjustment \\
\hline Arzt et al. ${ }^{39}$ & $\begin{array}{l}\text { General population } \\
\text { cohort, follow-up } \\
\text { at every } 4 \text { years }\end{array}$ & 1,189 & AHI $>20$ vs. $<5$ & $\begin{array}{l}\text { Incident stroke } \\
\text { OR, } 3.08(0.74-12.81)\end{array}$ & Age, sex, and BMI \\
\hline Redline et al. ${ }^{38}$ & $\begin{array}{l}\text { General population } \\
\text { cohort, (median) } \\
8.7 \text { year follow-up }\end{array}$ & 5,422 & AHI $>19$ vs. $<4$ & $\begin{array}{l}\text { Incident stroke } \\
\text { Men: HR, } 2.86(1.10-7.39) \\
\text { Women: HR, } 1.21(0.65-2.24)\end{array}$ & $\begin{array}{l}\text { Age, BMI, smoking, blood } \\
\text { pressure, antihypertensives, } \\
\text { diabetes mellitus, and race }\end{array}$ \\
\hline Marin et al. ${ }^{48}$ & $\begin{array}{l}\text { Clinic (OSA) and } \\
\text { general population } \\
\text { (control) cohort, } \\
10.1 \text { year } \\
\text { follow-up }\end{array}$ & $\begin{array}{l}1,010 \\
(\mathrm{men})\end{array}$ & $\begin{array}{l}\text { Untreated severe } \\
\text { OSA (AHI } \geq 30 \text { or } \\
\text { AHI 5-30 with } \\
\text { severe daytime } \\
\text { sleepiness) } \\
\text { vs. AHI <5 }\end{array}$ & $\begin{array}{l}\text { Incident composite } \\
\text { cardiovascular events } \\
\text { Non-fatal: OR, } 3.17(1.12-7.51) \\
\text { Fatal: OR, } 2.87(1.17-7.51)\end{array}$ & $\begin{array}{l}\text { Age, alcohol, smoking, } \\
\text { blood pressure, glucose, } \\
\text { diabetes mellitus, } \\
\text { cardiovascular disease, } \\
\text { hypertension, lipid } \\
\text { disorders, and lipid levels }\end{array}$ \\
\hline Munoz et al. ${ }^{40}$ & $\begin{array}{l}\text { Clinic cohort, } \\
\text { (mean) } 4.5 \text { year } \\
\text { follow-up }\end{array}$ & 394 & AHI $\geq 30$ vs. $0-29$ & $\begin{array}{l}\text { Incident stroke } \\
\mathrm{HR}, 2.52(1.04-6.10)\end{array}$ & $\begin{array}{l}\text { Sex (distribution of other } \\
\text { risk factors were balanced } \\
\text { between the two groups) }\end{array}$ \\
\hline Yaggi et al. ${ }^{37}$ & $\begin{array}{l}\text { Clinic cohort, } \\
\text { (median) } 3.4 \text { year } \\
\text { follow-up }\end{array}$ & 1,022 & $\mathrm{AHI}>5$ vs. $<5$ & $\begin{array}{l}\text { Incident stroke or death of } \\
\text { any causes } \\
\text { HR, } 1.97(1.12-3.48)\end{array}$ & $\begin{array}{l}\text { Age, race, sex, smoking, } \\
\text { alcohol, BMI, atrial } \\
\text { fibrillation, hypertension, } \\
\text { and lipids }\end{array}$ \\
\hline Yeboah et al. ${ }^{41}$ & $\begin{array}{l}\text { General population } \\
\text { cohort, (mean) } 7.5 \\
\text { year follow-up }\end{array}$ & 5,338 & $\begin{array}{l}\text { Physician } \\
\text { diagnosed OSA } \\
\text { vs. normal control }\end{array}$ & $\begin{array}{l}\text { Incident cardiovascular events } \\
\mathrm{HR}, 2.16(1.30-3.58) \\
\text { All-cause mortality } \\
\mathrm{HR}, 2.71 \text { (1.45-5.08) }\end{array}$ & $\begin{array}{l}\text { Age, gender, race/ethnicity, } \\
\text { smoking, alcohol, diabetes, } \\
\text { BMI, total cholesterol, } \\
\text { high-density lipoprotein, } \\
\text { triglyceride, and } \\
\text { benzodiazepine/statin/ } \\
\text { antihypertensive use }\end{array}$ \\
\hline Young et al. ${ }^{49}$ & $\begin{array}{l}\text { General population } \\
\text { cohort, } 18 \text { year } \\
\text { follow-up }\end{array}$ & 1,522 & AHI $\geq 30$ vs. $<5$ & $\begin{array}{l}\text { Cardiovascular mortality } \\
\text { HR, } 5.2(1.4-19.2) \\
\text { All-cause mortality } \\
\text { HR, } 3.8(1.6-9.0)\end{array}$ & $\begin{array}{l}\text { Age, sex, BMI, smoking, } \\
\text { alcohol, total cholesterol, } \\
\text { and sleep duration }\end{array}$ \\
\hline
\end{tabular}

*adjusted OR or HR (95\% confidence interval). AHI, apnea-hypopnea index; BMI, body mass index; HR, hazard ratio; OR, odds ratio; OSA, obstructive sleep apnea

이러한 폐쇄수면무호흡과 심뇌혈관질환의 밀접한 연관성 에도 불구하고 지속기도양압 치료와 심뇌혈관질환 발생과의 연관성에 대한 연구결과들은 아직 일정하지 않다. 숨골이 환 자와 일반인구집단을 대상으로 한 연구에서 심한 폐쇄수면 무호흡 $(\mathrm{AHI}>25)$ 환자는 심뇌혈관질환의 위험성이 높았으 며, 지속기도양압 치료를 시행 받은 사람은 심뇌혈관질환의 위험성이 낮았다. ${ }^{48}$ Wisconsin sleep cohort study에서도 폐 쇄수면무호흡을 적절하게 치료받지 않은 사람은 심뇌혈관질 환 사망 위험성이 높았다. ${ }^{49}$ 그러나 무작위 배정연구인 Sleep Apnea Cardiovascular Endpoints (SAVE) 임상시험에서는 지속기도양압 치료가 심뇌혈관질환의 발생위험을 낮추지 못하였다. ${ }^{50} \mathrm{SAVE}$ 임상연구에서는 지속기도양압 치료를 적 절하게(4시간 이상) 시행 받은 환자가 적었고 추적관찰 기간 도 짧았기 때문에 연구결과를 신중하게 해석할 필요가 있다

\section{고 고려된다.}

정확한 기전이 밝혀지지는 않았지만 상기도 폐쇄를 초래 하여 만성 간헐적 저산소증을 발생시킨다고 알려진 폐쇄수 면무호흡은 저산소증과 염증반응을 촉발하여 뇌와 뇌혈관에 악영향을 초래한다고 여겨진다. 동물실험에서 폐쇄수면무호 흡 환자처럼 간헐적으로 저산소증을 유발하면 인지기능저하, 수면주기의 변화, 수면부족에 대한 예민한 정도의 증가 등의 변화가 발생하는 것이 확인되었으며, ${ }^{51}$ 자유 라디칼, 지질의 과산화, 일산화질소의 발생, 세포자멸사 유도 등이 뇌혈관과 뇌실질을 손상시키는 기전으로 제시되었다. ${ }^{52}$ 또한, 폐쇄수면 무호흡은 염증, 혈관내피 기능이상, ${ }^{53}$ 과응고증, 뇌의 혈류변 화와 ${ }^{54}$ 연관되어 있다. 이러한 기전들은 실제 뇌졸중의 주요 기전이기도 하다(Fig. 1).

정리하자면 폐쇄수면무호흡은 여러 기전을 통하여 뇌졸중 
과 밀접하게 연관되어 있다. 또한 여러 논문에서 폐쇄수면무 호흡의 치료가 사망을 포함한 뇌졸중의 예후를 좋게 할 수 있음이 제시되었다. 따라서 뇌졸중환자에서는 폐쇄수면무호 흡 동반 여부를 주의 깊게 확인하고 진단이 된다면 적절하게 치료하여야 한다.

\section{급성 뇌졸중 환자에서 폐쇄수면무호흡}

급성 뇌졸중과 폐쇄수면무호흡 사이의 연관성 및 급성 뇌 졸중의 예후에 폐쇄수면무호흡이 미치는 영향 등을 확인한 연구는 많지 않다. 급성 뇌졸중 환자에서 중추성 및 폐쇄성 수면무호흡이 종종 보이는데도 불구하고 현실적으로 급성 뇌졸중 환자에게 수면다원검사를 적용하는 것이 쉽지 않기 때문에 대개 야간 산소포화도 측정 또는 이동식 수면다원검 사 결과를 이용한 연구들이 이루어진다. 비록 야간 산소포화 도와 수면다원검사를 이용하여 폐쇄수면무호흡 진단을 하 는 것에 대한 타당성 연구에서 야간 산소포화도를 이용하여 폐쇄수면무호흡을 예측하였을 때 심한 폐쇄수면무호흡증의 경우 $87 \%$ 의 진단 정확도를 보이긴 하였으나, 조금 더 정확한 진단과 다른 동반된 수면질환을 적절하게 평가하기 위해서 는 수면다원검사가 필수적이다. ${ }^{55}$

급성 뇌졸중 환자에게 지속기도양압 치료를 적용하는 자 체가 쉽지 않기 때문에 이 부분에 대한 연구결과는 많지 않 다. 폐쇄수면무호흡이 있는 급성 뇌경색 환자에게 지속기도 양압 치료를 하였을 때 30일 후 신경학적 증상의 의미있는 개선을 보였다. ${ }^{56}$ 또한, 뇌졸중 발생 후에 폐쇄수면무호흡이 보이는 환자들의 6 개월 째 사망률은 높았으며, 지속기도양압 치료를 하였을 때 상대적으로 뇌졸중의 재발이 적었다. ${ }^{57}$

이런 결과는 급성 뇌졸중 환자에서 폐쇄수면무호흡이 뇌
혈류의 빼앗김(arterial blood flow steal phenomenon) 현상 을 일으키는 것을 통해 설명할 수 있다. 폐쇄수면무호흡으로 인한 과탄산혈증은 뇌혈관의 확장을 초래하는데, 이때 뇌졸 중, 특히 뇌경색이 발생한 혈관뿐만 아니라 정상 뇌조직에 혈액을 공급하는 혈관도 확장되게 된다. 이런 이유로 오히려 정상 뇌조직에 혈액을 공급하는 혈관으로 더욱 혈류가 증가 되게 되고 뇌경색이 발생한 혈관에는 혈류가 감소하게 된다. 이러한 현상을 소위 reverse Robin Hood syndrome이라고 부르기도 한다(Fig. 2). 이러한 폐쇄수면무호흡으로 인한 뇌 혈류의 빼앗김 현상은 뇌졸중의 조기 악화나, 좋지 않은 예 후와 밀접하게 연관되어 있다. ${ }^{58}$

\section{양압기 중단이 심뇌혈관계 미치는 영향}

지속기도양압 치료가 고혈압, 당뇨, 심방세동, 뇌졸중에 효 과적임을 증명한 연구는 앞서 언급한 것과 같이 다양하게 존 재한다. 하지만 종종 발생하는 지속기도양압 치료 순응도 감 소로 인해 지속기도양압 치료효과의 평가는 어렵다. 따라서 적절하게 지속기도양압 치료중인 환자에서 지속기도양압 치 료를 중단하였을 때 발생하는 영향을 분석한 연구들을 이 종 설에서 같이 소개하고자 한다.

폐쇄수면무호흡을 가지는 환자에서 지속기도양압 치료를 2주 동안 중단 하였을 때, 폐쇄수면무호흡의 재발, 주간졸림 증(daytime sleepiness)의 증가, 교감활성의 표지자(markers of sympathetic activity) 증가, 수축기 및 이완기 혈압 상승, 혈관 내피세포의 기능장애, 심실벽 내의 재분극 분산도(dispersion of transmural cardiac repolarization)의 상승이 관찰 되었다. 또한 2주간의 지속기도양압 치료 중단은 저산소 전 처리(hypoxic pre-conditioning)의 표지자인 superoxide dis-

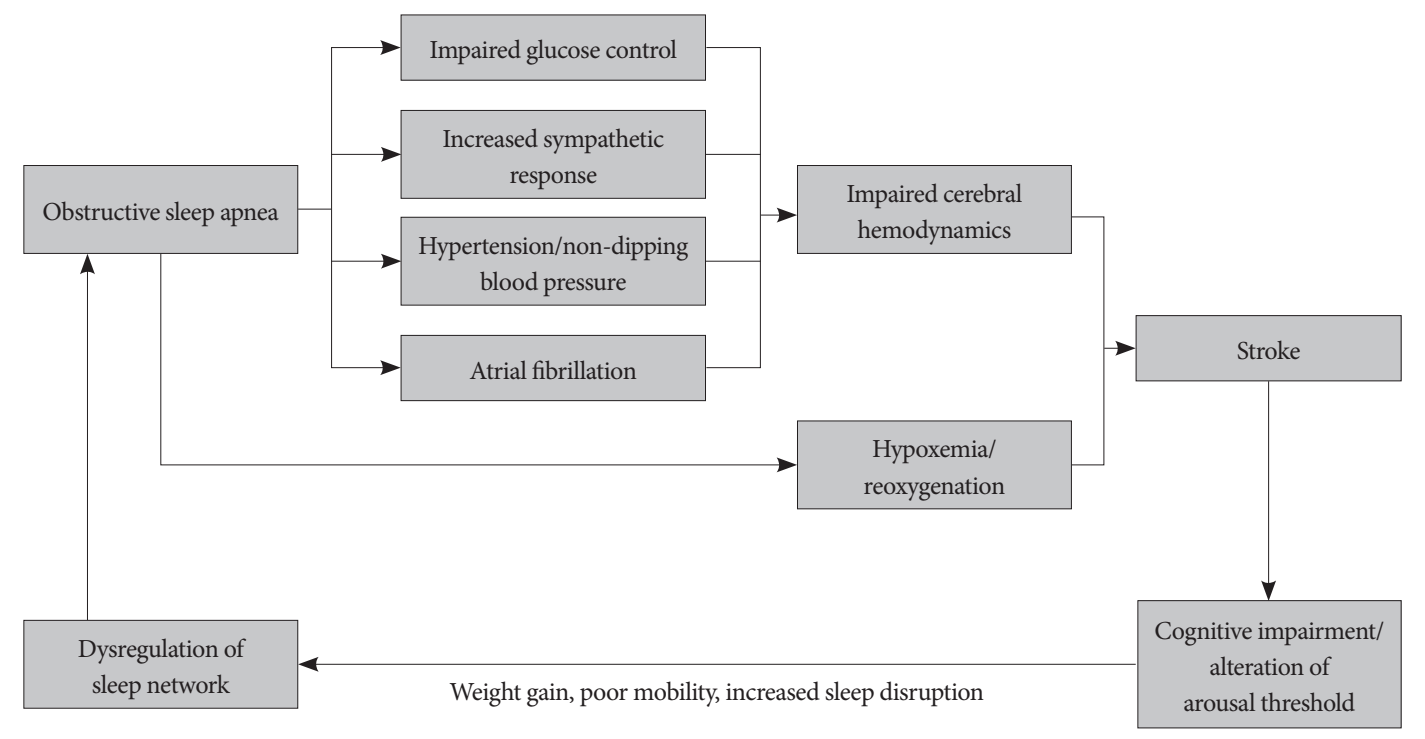

Figure 1. Illustrating the association between obstructive sleep apnea and stroke. 

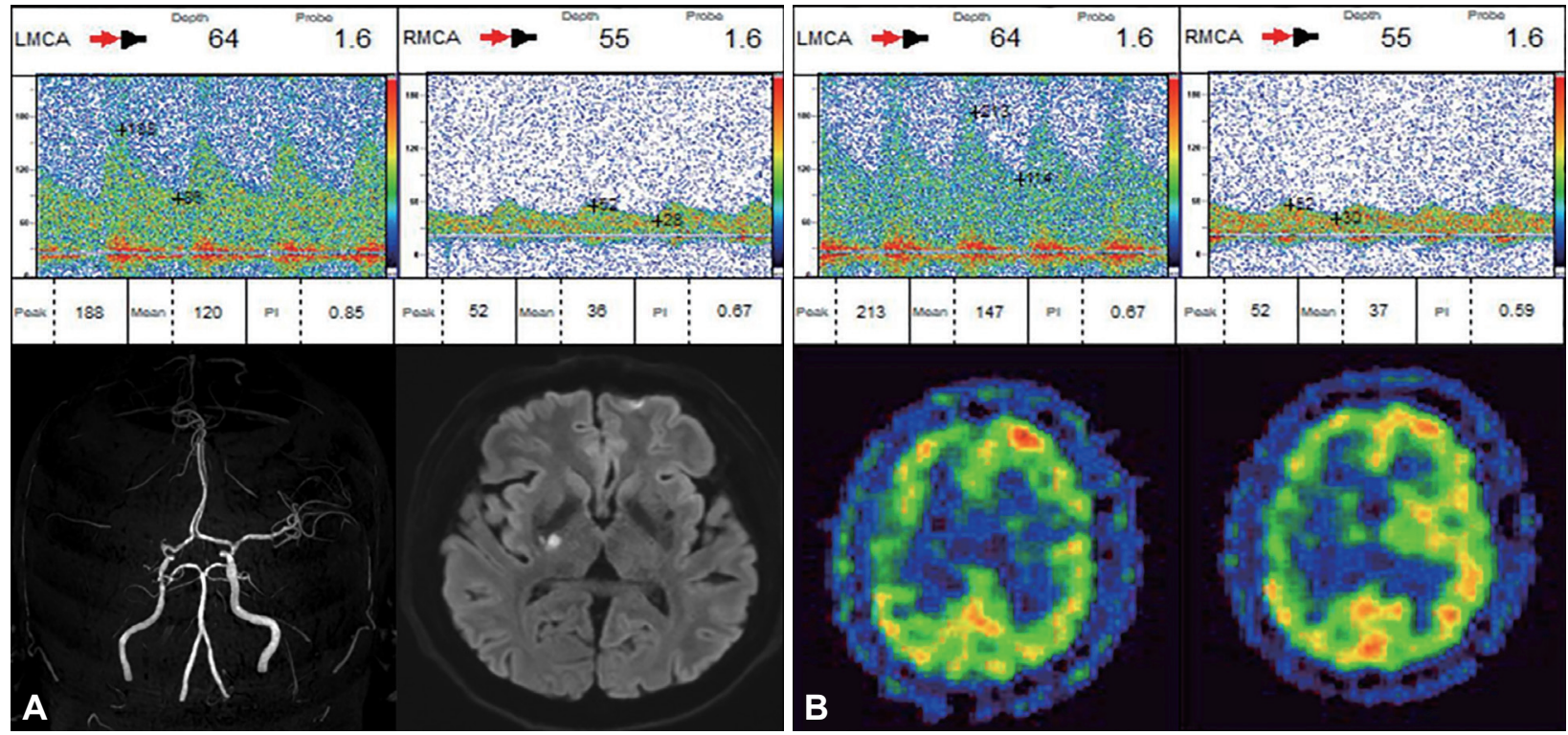

Figure 2. Illustrating reverse Robin Hood syndrome. A: Spontaneous fluctuating flow velocity and flow diversion without breath-holding on transcranial Doppler monitoring in patient with right middle cerebral artery (MCA) occlusion and acute infarction in the right internal capsule. B: Increased mean flow velocity on left MCA and decreased mean flow velocity on right MCA for breath-holding on bilateral MCA monitoring and brain single photon emission computed tomography with and without Diamox infusion in patient with right MCA occlusion. Hypercapnia for breath-holding can decrease the flow velocity in the affected vessel of ischemic brain at the time of normal vessel dilation when blood is moved to non-affected brain. We call this steal phenomenon "reverse Robin Hood syndrome".

mutase의 수치를 증가시킨다. 하지만 2주간의 지속기도양압 치료 중단이 심근혈류(myocardial blood flow)에는 영향을 미치지 않아, 지속기도양압 치료를 중단하는 동안 폐쇄수면 무호흡이 급성심근허혈(acute myocardial ischemia)은 일으 키지 않는다고 생각된다. ${ }^{59}$ 또한, 중증 폐쇄수면무호흡 환자 를 대상으로 지속기도양압 치료를 유지한 그룹과 중단한 그 룹을 비교한 연구에서 지속기도양압 치료를 유지한 그룹에 서 인슐린 민감도가 $13.3 \%$ 호전되었으며, 지속기도양압 치료 2시간 후 인슐린 수치가 $28.7 \%$ 감소되는 모습을 보였다. ${ }^{60}$

\section{결 론}

폐쇄수면무호흡은 자율신경기능이상을 초래하며, 이로 인 한 고혈압, 혈당증가, 심방세동 등의 뇌졸중의 위험인자와 밀 접하게 연관되어 있다. 또한 폐쇄수면무호흡은 독립적으로 뇌졸중과 연관되어 있으며, 또한 뇌졸중의 조기악화, 좋지 않 은 예후, 장기적인 심뇌혈관질환 발생 및 사망과도 관련되어 있다. 따라서 뇌졸중 환자에서는 폐쇄수면무호흡의 동반여 부를 반드시 확인하고, 폐쇄수면무호흡이 진단된다면 적절한 치료를 시행해야 한다. 비록 지속기도양압 치료에 대한 효과 및 중단 시 발생하는 악화에 대한 연구결과가 많지 않은 상황 이지만 여러 연구에 따르면 뇌졸중 환자에서 폐쇄수면무호 흡이 동반된 경우 지속기도양압 치료가 도움이 될 수 있다.

\section{Conflicts of Interest}

The authors have no potential conflicts of interest to disclose.

\section{ORCID iDs}

$\begin{array}{ll}\text { Ho Geol Woo } & \text { https://orcid.org/0000-0001-6489-0100 } \\ \text { Kwang Ik Yang } & \text { https://orcid.org/0000-0001-6343-6520 } \\ \text { Tae-Jin Song } & \text { https://orcid.org/0000-0002-9937-762X }\end{array}$

\section{Author Contributions}

Conceptualization: Ho Geol Woo. Data curation: Ho Geol Woo, Tae-Jin Song. Formal analysis: all authors. Investigation: all authors. Methodology: all authors. Project administration: all authors. Supervision: Kwang Ik Yang, Tae-Jin Song. Visualization: Ho Geol Woo. Writing-original draft: Ho Geol Woo. Writing—review \& editing: all authors.

\section{Funding Statement}

None.

\section{REFERENCES}

1. Thorpy MJ. History of sleep medicine. Handb Clin Neurol 2011;98:325. https://doi.org/10.1016/B978-0-444-52006-7.00001-0.

2. Gastaut H, Tassinari CA, Duron B. [Polygraphic study of diurnal and nocturnal (hypnic and respiratory) episodal manifestations of Pickwick syndrome]. Rev Neurol (Paris) 1965;112:568-579.

3. Guilleminault C, Eldridge F, Dement WC. Insomnia, narcolepsy, and sleep apneas. Bull Physiopathol Respir (Nancy) 1972;8:1127-1138.

4. Yang KI, Jung KY. Proposal for changing the Korean terminology of snoring. J Sleep Med 2021;18:58-59. https://doi.org/10.13078/jsm.210011.

5. Sateia MJ. International classification of sleep disorders-third edition: highlights and modifications. Chest 2014;146:1387-1394. https:/doi. org/10.1378/chest.14-0970.

6. Sullivan CE, Issa FG, Berthon-Jones M, Eves L. Reversal of obstructive sleep apnoea by continuous positive airway pressure applied through 
the nares. Lancet 1981;1:862-865.

7. Lugaresi E, Cirignotta F, Coccagna G, Piana C. Some epidemiological data on snoring and cardiocirculatory disturbances. Sleep 1980;3:221224. https://doi.org/10.1093/sleep/3.3-4.221.

8. Gillis AM. Cardiac arrhythmias during sleep. Compr Ther 1985;11:6671.

9. D’Alessandro R, Magelli C, Gamberini G, et al. Snoring every night as a risk factor for myocardial infarction: a case-control study. BMJ 1990; 300:1557-1558. https://doi.org/10.1136/bmj.300.6739.1557-a.

10. Partinen M, Palomäki H. Snoring and cerebral infarction. Lancet 1985; 2:1325-1326. https://doi.org/10.1016/s0140-6736(85)92625-x.

11. Sunwoo JS, Hwangbo Y, Kim WJ, Chu MK, Yun CH, Yang KI. Prevalence, sleep characteristics, and comorbidities in a population at high risk for obstructive sleep apnea: a nationwide questionnaire study in South Korea. PLoS One 2018;13:e0193549. https://doi.org/10.1371/ journal.pone.0193549.

12. Yang KI. What obstructive sleep apnea brings to us. J Korean Neurol Assoc 2013;31:93-100.

13. Sunwoo JS, Yang KI. Overview of treatment for obstructive sleep apnea in adults. J Sleep Med 2017;14:1-9. https://doi.org/10.13078/jsm.17001.

14. Fletcher EC, DeBehnke RD, Lovoi MS, Gorin AB. Undiagnosed sleep apnea in patients with essential hypertension. Ann Intern Med 1985; 103:190-195. https://doi.org/10.7326/0003-4819-103-2-190.

15. Walia HK, Li H, Rueschman M, et al. Association of severe obstructive sleep apnea and elevated blood pressure despite antihypertensive medication use. J Clin Sleep Med 2014;10:835-843. https://doi.org/10.5664/ jcsm.3946.

16. Nieto FJ, Young TB, Lind BK, et al. Association of sleep-disordered breathing, sleep apnea, and hypertension in a large community-based study. Sleep Heart Health Study. JAMA 2000;283:1829-1836. https:// doi.org/10.1001/jama.283.14.1829.

17. Hla KM, Young T, Finn L, Peppard PE, Szklo-Coxe M, Stubbs M. Longitudinal association of sleep-disordered breathing and nondipping of nocturnal blood pressure in the Wisconsin Sleep Cohort Study. Sleep 2008;31:795-800. https://doi.org/10.1093/sleep/31.6.795.

18. Narkiewicz K, Montano N, Cogliati C, van de Borne PJ, Dyken ME, Somers VK. Altered cardiovascular variability in obstructive sleep apnea. Circulation 1998;98:1071-1077. https://doi.org/10.1161/01.cir.98.11.1071.

19. Marin JM, Agusti A, Villar I, et al. Association between treated and untreated obstructive sleep apnea and risk of hypertension. JAMA 2012; 307:2169-2176. https://doi.org/10.1001/jama.2012.3418.

20. Martínez-García MA, Capote F, Campos-Rodríguez F, et al. Effect of CPAP on blood pressure in patients with obstructive sleep apnea and resistant hypertension: the HIPARCO randomized clinical trial. JAMA 2013;310:2407-2415. https://doi.org/10.1001/jama.2013.281250.

21. Punjabi NM, Shahar E, Redline S, Gottlieb DJ, Givelber R, Resnick HE. Sleep-disordered breathing, glucose intolerance, and insulin resistance: the Sleep Heart Health Study. Am J Epidemiol 2004;160:521-530. https://doi.org/10.1093/aje/kwh261.

22. Rasche K, Keller T, Tautz B, et al. Obstructive sleep apnea and type 2 diabetes. Eur J Med Res 2010;15 Suppl 2:152-156. https://doi.org/10.1186/2047783x-15-s2-152.

23. Foster GD, Sanders MH, Millman R, et al. Obstructive sleep apnea among obese patients with type 2 diabetes. Diabetes Care 2009;32:10171019. https://doi.org/10.2337/dc08-1776.

24. Martínez-Cerón E, Barquiel B, Bezos AM, et al. Effect of continuous positive airway pressure on glycemic control in patients with obstructive sleep apnea and type 2 diabetes. A randomized clinical trial. Am J Respir Crit Care Med 2016;194:476-485. https://doi.org/10.1164/rccm.2015101942OC.

25. Mokhlesi B, Grimaldi D, Beccuti G, et al. Effect of one week of 8-hour nightly continuous positive airway pressure treatment of obstructive sleep apnea on glycemic control in type 2 diabetes: a proof-of-concept study. Am J Respir Crit Care Med 2016;194:516-519. https://doi.org/10.1164/ rccm.201602-0396LE.
26. Hindricks G, Potpara T, Dagres N, et al. 2020 ESC Guidelines for the diagnosis and management of atrial fibrillation developed in collaboration with the European Association for Cardio-Thoracic Surgery (EACTS): the task force for the diagnosis and management of atrial fibrillation of the European Society of Cardiology (ESC) developed with the special contribution of the European Heart Rhythm Association (EHRA) of the ESC. Eur Heart J 2021;42:373-498. https://doi.org/10.1093/eurheartj/ ehaa612.

27. Mehra R, Benjamin EJ, Shahar E, et al. Association of nocturnal arrhythmias with sleep-disordered breathing: the Sleep Heart Health Study. Am J Respir Crit Care Med 2006;173:910-916. https://doi.org/10.1164/ rccm.200509-1442OC.

28. Yamashita T, Murakawa Y, Sezaki K, et al. Circadian variation of paroxysmal atrial fibrillation. Circulation 1997;96:1537-1541. https://doi. org/10.1161/01.cir.96.5.1537.

29. Hoffstein V, Mateika S. Cardiac arrhythmias, snoring, and sleep apnea. Chest 1994;106:466-471. https://doi.org/10.1378/chest.106.2.466.

30. Mooe T, Gullsby S, Rabben T, Eriksson P. Sleep-disordered breathing: a novel predictor of atrial fibrillation after coronary artery bypass surgery. Coron Artery Dis 1996;7:475-478.

31. Linz D, Schotten U, Neuberger HR, Böhm M, Wirth K. Negative tracheal pressure during obstructive respiratory events promotes atrial fibrillation by vagal activation. Heart Rhythm 2011;8:1436-1443. https:// doi.org/10.1016/j.hrthm.2011.03.053.

32. Chang SL, Chen YC, Chen YJ, et al. Mechanoelectrical feedback regulates the arrhythmogenic activity of pulmonary veins. Heart 2007;93: 82-88. https://doi.org/10.1136/hrt.2006.089359.

33. Virolainen J, Ventilä M, Turto H, Kupari M. Influence of negative intrathoracic pressure on right atrial and systemic venous dynamics. Eur Heart J 1995;16:1293-1299. https://doi.org/10.1093/oxfordjournals. eurheartj.a061088.

34. Kanagala R, Murali NS, Friedman PA, et al. Obstructive sleep apnea and the recurrence of atrial fibrillation. Circulation 2003;107:2589-2594. https://doi.org/10.1161/01.CIR.0000068337.25994.21.

35. Patel D, Mohanty P, Di Biase L, et al. Safety and efficacy of pulmonary vein antral isolation in patients with obstructive sleep apnea: the impact of continuous positive airway pressure. Circ Arrhythm Electrophysiol 2010;3:445-451. https://doi.org/10.1161/CIRCEP.109.858381.

36. Brown DL, Levine DA, Albright $\mathrm{K}$, et al. Benefits and risks of dual versus single antiplatelet therapy for secondary stroke prevention: a systematic review for the 2021 guideline for the prevention of stroke in patients with stroke and transient ischemic attack. Stroke 2021;52:e468e479. https://doi.org/10.1161/STR.0000000000000377.

37. Yaggi HK, Concato J, Kernan WN, Lichtman JH, Brass LM, Mohsenin V. Obstructive sleep apnea as a risk factor for stroke and death. $N$ Engl J Med 2005;353:2034-2041. https://doi.org/10.1056/NEJMoa043104.

38. Redline S, Yenokyan G, Gottlieb DJ, et al. Obstructive sleep apnea-hypopnea and incident stroke: the sleep heart health study. Am J Respir Crit Care Med 2010;182:269-277. https://doi.org/10.1164/rccm.2009111746OC.

39. Arzt M, Young T, Finn L, Skatrud JB, Bradley TD. Association of sleepdisordered breathing and the occurrence of stroke. Am J Respir Crit Care Med 2005;172:1447-1451.

40. Munoz R, Duran-Cantolla J, Martinez-Vila E, et al. Severe sleep apnea and risk of ischemic stroke in the elderly. Stroke 2006;37:2317-2321.

41. Yeboah J, Redline S, Johnson C, et al. Association between sleep apnea, snoring, incident cardiovascular events and all-cause mortality in an adult population: MESA. Atherosclerosis 2011;219:963-968.

42. Minoguchi K, Yokoe T, Tazaki T, et al. Silent brain infarction and platelet activation in obstructive sleep apnea. Am J Respir Crit Care Med 2007;175:612-617. https://doi.org/10.1164/rccm.200608-1141OC.

43. Koo DL, Kim JY, Lim JS, Kwon HM, Nam H. Cerebral microbleeds on MRI in patients with obstructive sleep apnea. J Clin Sleep Med 2017; 13:65-72. https://doi.org/10.5664/jcsm.6390.

44. Song TJ, Park JH, Choi KH, et al. Moderate-to-severe obstructive sleep 
apnea is associated with cerebral small vessel disease. Sleep Med 2017; 30:36-42. https://doi.org/10.1016/j.sleep.2016.03.006.

45. Song TJ, Park JH, Choi KH, et al. Is obstructive sleep apnea associated with the presence of intracranial cerebral atherosclerosis? Sleep Breath 2017;21:639-646. https://doi.org/10.1007/s11325-016-1450-9.

46. Yun $\mathrm{CH}$, Jung $\mathrm{KH}$, Chu K, et al. Increased circulating endothelial microparticles and carotid atherosclerosis in obstructive sleep apnea. $J$ Clin Neurol 2010;6:89-98. https://doi.org/10.3988/jcn.2010.6.2.89.

47. Woo HG, Song TJ, Jung JS, et al. Association between the high risk for obstructive sleep apnea and intracranial carotid artery calcification in patients with acute ischemic stroke. Sleep Breath 2021;25:299-307. https://doi.org/10.1007/s11325-020-02117-x.

48. Marin JM, Carrizo SJ, Vicente E, Agusti AG. Long-term cardiovascular outcomes in men with obstructive sleep apnoea-hypopnoea with or without treatment with continuous positive airway pressure: an observational study. Lancet 2005;365:1046-1053. https://doi.org/10.1016/ S0140-6736(05)71141-7.

49. Young T, Finn L, Peppard PE, et al. Sleep disordered breathing and mortality: eighteen-year follow-up of the Wisconsin sleep cohort. Sleep 2008;31:1071-1078. https://doi.org/10.5665/sleep/31.8.1071.

50. McEvoy RD, Antic NA, Heeley E, et al. CPAP for prevention of cardiovascular events in obstructive sleep apnea. N Engl J Med 2016;375:919931. https://doi.org/10.1056/NEJMoa1606599.

51. Sanfilippo-Cohn B, Lai S, Zhan G, et al. Sex differences in susceptibility to oxidative injury and sleepiness from intermittent hypoxia. Sleep 2006;29:152-159. https://doi.org/10.1093/sleep/29.2.152.

52. Xu W, Chi L, Row BW, et al. Increased oxidative stress is associated with chronic intermittent hypoxia-mediated brain cortical neuronal cell apoptosis in a mouse model of sleep apnea. Neuroscience 2004;126: 313-323. https://doi.org/10.1016/j.neuroscience.2004.03.055.
53. Wang J, Yu W, Gao M, et al. Impact of obstructive sleep apnea syndrome on endothelial function, arterial stiffening, and serum inflammatory markers: an updated meta-analysis and metaregression of 18 studies. J Am Heart Assoc 2015;4:e002454. https://doi.org/10.1161/ JAHA.115.002454.

54. Diomedi M, Placidi F, Cupini LM, Bernardi G, Silvestrini M. Cerebral hemodynamic changes in sleep apnea syndrome and effect of continuous positive airway pressure treatment. Neurology 1998;51:1051-1056. https://doi.org/10.1212/wnl.51.4.1051.

55. Hang LW, Wang HL, Chen JH, et al. Validation of overnight oximetry to diagnose patients with moderate to severe obstructive sleep apnea. BMC Pulm Med 2015;15:24. https://doi.org/10.1186/s12890-015-0017-z.

56. Bravata DM, Concato J, Fried T, et al. Continuous positive airway pressure: evaluation of a novel therapy for patients with acute ischemic stroke. Sleep 2011;34:1271-1277. https://doi.org/10.5665/SLEEP.1254.

57. Turkington PM, Allgar V, Bamford J, Wanklyn P, Elliott MW. Effect of upper airway obstruction in acute stroke on functional outcome at 6 months. Thorax 2004;59:367-371. https://doi.org/10.1136/thx.2003.005348.

58. Alexandrov AV, Sharma VK, Lao AY, Tsivgoulis G, Malkoff MD, Alexandrov AW. Reversed Robin Hood syndrome in acute ischemic stroke patients. Stroke 2007;38:3045-3048. https://doi.org/10.1161/ STROKEAHA.107.482810.

59. Schwarz EI, Stradling JR, Kohler M. Physiological consequences of CPAP therapy withdrawal in patients with obstructive sleep apnoeaan opportunity for an efficient experimental model. J Thorac Dis 2018; 10:S24-S32. https://doi.org/10.21037/jtd.2017.12.142.

60. Weinstock TG, Wang X, Rueschman M, et al. A controlled trial of CPAP therapy on metabolic control in individuals with impaired glucose tolerance and sleep apnea. Sleep 2012;35:617-625. https://doi. org/10.5665/sleep.1816. 